\title{
Research Rating Anglistik/Amerikanistik of the German Council of Science and Humanities
}

\author{
Alfred Hornung, Veronika Khlavna and Barbara Korte
}

\begin{abstract}
The pilot study Forschungsrating Anglistik/Amerikanistik is the first implementation of the Forschungsrating in the humanities. This chapter presents the findings and conclusions of the rating. It consists of three parts: First, the results of the rating, first published in December 2012, are presented, as well as the conclusions drawn by the German Council of Science and Humanities. Second, Alfred Hornung who chaired the review board reflects on the Forschungsrating from the point of view of the chair of the review board as well as an Amerikanistik scholar. Third, Barbara Korte writes about the Forschungsrating from her perspective as a member of the review board and Anglistik scholar.
\end{abstract}

\section{Research Rating in English and American Studies (by Veronika Khlavna and Alfred Hornung)}

\subsection{Introduction}

In May 2008, the German Council for Science and Humanities, which provides advice to the German Federal Government and the State (Länder) Governments on the structure and development of higher education and research, decided to extend its pilot studies of research rating in the fields of Chemistry and Sociology to the

\footnotetext{
A. Hornung $(\varangle)$

Department of English and Linguistics, American Studies, Johannes Gutenberg

University Mainz, Jakob-Welder-Weg 18 (Philosophicum), Raum 01-597,

55099 Mainz, Germany

e-mail: hornung@uni-mainz.de

V. Khlavna

Research Policy Department, German Council of Science and Humanities,

50968 Cologne, Germany

e-mail:khlavna@wissenschaftsrat.de

B. Korte

University of Freiburg, English Seminar, Rempartstr. 15, 79098 Freiburg, Germany

e-mail: barbara.korte@ anglistik.uni-freiburg.de 
fields of Technical Sciences and the Humanities (Wissenschaftsrat 2008, pp. 11-17). The overall goal was to test the applicability of research rating methods also in the Humanities. The disciplines selected were Anglistik/Amerikanistik, which comprises the subfields of English linguistics, English-language literatures and cultures, American Studies, and English didactics. ${ }^{1}$ The results of this research rating of Anglistik/Amerikanistik were published in December 2012 (Wissenschaftsrat 2013, pp. 271-333). ${ }^{2}$

The pilot study of the research rating in the discipline of English and American Studies builds on the methodologies and criteria of procedure developed in conjunction with the pilot studies in Chemistry, Sociology, and Electrical and Computer Engineering. ${ }^{3}$ One of the most important and essential features of the research rating is that its procedure is explicitly designed by academic standards. Academic standards for the research rating are guaranteed by male and female evaluators in review boards as well as by the respective academic associations. The responsibility for the first pilot study of the research rating and its further development were in the hands of a steering group consisting of the members of the scientific commission of the Wissenschaftsrat, individual and institutional members of the major science organizations as well as guests from state ministries and the Federal Ministry for Education and Research. As in the previous pilot studies, the steering group entrusted a review board with the implementation of the research rating for English and American Studies. The scientific organizations and professional associations were asked to nominate potential reviewers with an international reputation who could cover the most important subfields. The review board on English and American Studies, chaired by Prof. Dr. Alfred Hornung, consisted of 19 members. The main objectives of the review board were the definition of the field Anglistik/Amerikanistik and its subfields, the determination of criteria for application in the review process, the creation of appropriate questionnaires and the eventual assessments.

Based on the assumption that universities and other academic institutions pursue research in their respective fields and beyond, the assessment of research performance in English and American Studies followed the convention established in the other pilot studies and applied multiple criteria of evaluation, each of them specified by several aspects and operationalized by different quantitative and qualitative data.

\footnotetext{
${ }^{1}$ All institutions active in the research of at least one of the defined subfields were able to participate in the research rating of Anglistik/Amerikanistik. The time period chosen for the assessment was 7 years (1 January 2004-31 December 2010). To participate institutions had to have existed for at least half of the survey period. No other criteria, such as minimum number of personnel, were determined. As in the previous pilot studies, the response to the research rating was also very high in English and American Studies. 358 participating professors at the reporting date in 2010 represent $94 \%$ of the 379 professors registered by the Federal Statistical Office for Teaching and Research in 'English and American Studies' (see Statistisches Bundesamt 2010, p. 94).

${ }^{2}$ The results of the participating institutions can be found at: http://www.wissenschaftsrat.de/nc/ arbeitsbereiche-arbeitsprogramm/forschungsrating/anglistikamerikanistik.html.

${ }^{3}$ See Wissenschaftsrat $(2008,2013)$.
} 
As in the previous pilot studies, the assessment of the research performance was based on an informed peer-review process by expert reviewers. For each evaluated institution, the reviewers received extensive data with quantitative and qualitative information.

In the following, the levels of the research ratings in English and American Studies and the experiences made in the review process will be outlined and explained. Subsequently, the criteria will be described. The last part will give an outlook on further procedures.

\subsection{Procedural Steps}

As in other disciplines, the implementation of the research rating in English and American Studies can be subdivided into four phases: 1. subject-specific operationalization, 2. collection of data from the institutions, 3. assessment of the data reviewed by the review board, 4. publication of the results and recommendations for the procedure.

\subsubsection{Subject-Specific Operationalization}

The subject-specific adaptation of the research rating to English and American Studies included the definition of the field and the subfields, the definition of the criteria and the data, the terms for the participation as well as the preparation of the data collection. The definition of the discipline and its subfields in English and American Studies agreed upon by the review board proved to be adequate and manageable. For comparison purposes the established definitions of the subfields (English linguistics, English Studies: Literature and Cultural Studies, American Studies, Didactics of English) should be reused in future research ratings of English and American Studies. At present the adequate assessment of interdisciplinary research is an area of concern. In order to reflect the different roles and profiles of institutions and to identify their strengths and weaknesses, the research achievements in English and American Studies were also evaluated according to multiple criteria (research quality, reputation, facilitating research and transfer to non-university recipients), each of them with differentiating aspects of assessment. These were mostly operationalized by qualitative information. The background information provided by the institutions on human resources and teaching workloads permitted the contextualization of the data with regard to research activities.

\subsubsection{Collection of Data from Institution}

The collection of publication lists and data in the institutions were based on the current-potential principle (the status of performance of actively employed scholars 
at a respective institution on the reporting date of 31 December 2010 over the past 7 year period). The work-done-at principle was applied in cases where not all relevant data was available at the reporting date (performance of all scholars employed at the given institution in the 7 year period from 01 January 2004 to 31 December 2010). Thus, the data collection was based on the 'hybrid' approach of current-potential and work-done-at.

The data collection followed three steps: 1. personnel data, 2. publication data and 3. main data collection. In a first step, the institutions classified scholars actively engaged in English and American Studies according to professional positions, and assigned them to the four subfields. Subsequently, the institutions were asked to submit for each professor three exemplary publications from the survey period. In the course of the subsequent main data collection all other data relevant to the assessment were collected.

Except for the exemplary publications, the data of the institutions were collected in online questionnaires.

\subsubsection{Assessment of the Data by the Review Board}

As in previous pilot studies, the methods and the informed peer-review approach proved to be successful. The assessment was carried out in three steps: First, the two reviewers assigned to respective institutions reviewed the publications and data individually and independent of each other for a preliminary assessment prior to the meetings of the review board. At the meetings the review board formed two separate panels to discuss the preliminary results in subfield-specific groups. Thus English Studies: Literature and Cultural Studies joined up with American Studies, English linguistics with Didactics of English. In a final step, all reviews were put to vote in the general meetings of the plenum.

All criteria were evaluated on the level of the subfields to adequately account for the constitution of the field. After a first review of the data and in preparation for the assessment phase, the reviewers of the respective subfields met with the staff from the Office of the German Council of Science and Humanities to develop criteria for a subfield-specific assessment. This procedure allowed an early analysis of the data material and provided an appropriate access for the assessment of the individual subfields. This approach proved to be successful and should be applied in the future with particular attention to the consolidation of the results gained in subfield-specific meetings with the collectively defined criteria in the review board.

The data assembled for the assessment proved to be of different relevance. While the data collected for the assessment of the criteria 'research quality' and 'facilitating research' provided a solid and reliable basis, the assessment of the criteria of 'reputation' and 'transfer to non-university recipients' was less reliable, also due to some incomplete data. In general, the assessment model however worked out and should be retained with respect to the adjustments recommended in the Final Report of the Review Board (Wissenschaftsrat 2013, pp.219-271). Efficiency measures were not calculated. The background information provided turned out to be helpful for the 
qualification and contextualization of the other data. The high degree of agreement between the reviewers in their rating is a strong support for the reliability of the informed peer-review process.

\subsubsection{Publication of Results}

As in the previous pilot studies, the publication of the results consisted of two parts, the result report (Wissenschaftsrat 2013, pp.271-333) and the institution-based presentation of results. The results are also available online ${ }^{4}$ and allow a direct comparison of the institutions on the level of the different criteria for the four defined subfields.

\subsection{Criteria}

In line with the rating procedure the following criteria were used for the assessment of English and American Studies: 'research quality', 'reputation', 'facilitating research' and 'transfer to non-university recipients'.

\subsubsection{Research Quality}

Quality of research is of particular importance in the assessment of research performance. Contrary to previous pilot studies, the assessment of the criterion 'quality of research' was primarily based on the assessment of the quality of the publication output. In addition, information on the quantity of the publication output was used. The focus on a qualitative assessment of the publications in English and American Studies was necessary because a citation-based performance assessment of publications does not exist, which is the case in many disciplines of the humanities. ${ }^{6}$

The qualitative assessment of publication performance was primarily based on the reading of the submitted exemplary publications. For this purpose, each professor

\footnotetext{
${ }^{4}$ The general results are published at www.forschungsrating.de. The results of the participating institutions can be found at: http://www.wissenschaftsrat.de/nc/arbeitsbereiche-arbeitsprogramm/ forschungsrating/anglistikamerikanistik.html.

${ }^{5}$ The complete scoring matrix is available at: http://www.wissenschaftsrat.de/download/ Forschungsrating/Dokumente/Bewertungsmatrix_ANAM.pdf.

${ }^{6}$ There are many reasons for the absence of citation indexes: lists of books and monographs in publication and citation databases are often incomplete, publications tended to be in German and hence did not figure in international citation databases, collections of essays and anthologies are not systematically evaluated, the number of citations is no clear information on the quality of a publication, since a citation can indicate both an appreciation and a critique of the respective research positions, and finally there does not seem to exist a unanimous opinion on a quality ranking of journals and other publications.
} 
could submit three publications or publication excerpts of max 50 pages. One of the publications could be that of a young academic affiliated with the professorship. This procedure and, in particular, the possibility of considering a publication of young scholars proved to be advantageous. The assessment of publication excerpts, especially those from monographs, proved to be difficult when the reviewers did not know the complete publication. In the future it should be possible to submit the monograph and to mark the section of about 50 pages to be considered in the assessment. The qualitative assessment of the publication lists and their quantitative information (number of publications according to publication types) enhanced the reading of the submitted exemplary publications. The criteria relevant for the assessment of the publications, namely 'importance', 'degree of innovation', 'originality', 'timeliness', 'impact' (national and international), 'quality of research methods' and the range and influence of the research question for one's own discipline as well as for other fields proved to be adequate.

\subsection{2 'Reputation'}

The assessment of the criterion of 'reputation' was entirely based on qualitative information given for the assessment aspects of 'recognition' and 'professional activities'. The submitted entries for this criterion were very heterogeneous in terms of quality and quantity which rendered its assessment more difficult. The assessment of data given for 'recognition' proved to be especially difficult. Overall, the assessment of 'reputation' as a separate criterion was justified. To improve data quality, the definition of this criterion and its aspects should be more specified in the future, prior to the collection of data.

\subsection{3 'Facilitating Research'}

The assessment of 'facilitating research' intended to account for activities immanent in academic fields which enable the performance of research in the first place. ${ }^{7}$ The evaluation aspects ( 'third-party funding', 'young talent', 'infrastructure and networks') and data selected for the assessment of this criterion proved appropriate. Particularly the quantitative data and indicators contributed to the simplification and transparency of the ratings.

The data collected for funding sources and the years of the expenditure of thirdparty funds was relatively unproblematic for the individual subfields. A possibility to optimize the collection of information on third-party funding activities might be the adaptation of the collection principle for the externally funded projects and the expended third-party funds. Since the records covered externally funded projects granted during the survey period on the one hand and the expenditure of third-party

\footnotetext{
${ }^{7}$ Refer to Wissenschaftsrat recommendations for comparative research assessment in the humanities (Wissenschaftsrat 2013, pp.345-367).
} 
funds in each year of the survey period on the other, a connection between the two pieces of information was difficult to assess.

The lists of current doctoral dissertations submitted by the institutions proved to be inconclusive. The assessment of these lists was difficult as the successful graduation can actually not be predicted. Accordingly, this data had lesser importance in the assessment process. At the beginning of the review process, the review board had decided not to assess the achievements in the promotion of young talent on the basis of the number of granted $\mathrm{PhDs}$ since this figure just provides information about the quantity but not the quality of the young talent. This approach proved appropriate. To allow a more precise assessment of the success of support for the young talent, this information should still be supplemented by quantitative details of completed PhDs in the future. For the assessment of the achievements of the promotion of the young talent, the collected qualitative information (name of the doctoral candidate, name of the supervisor, title and year) of completed dissertations were more important for the assessment process than information on ongoing dissertations.

An adequate assessment of information on networks and research collaborations, in which the reported scholars were significantly involved, was difficult because of the great heterogeneity of the entries and their varied significance. In some cases, major national and international networks, associations and research centres figured next to less significant and informal networks. In the future, this data should be more distinctively described.

\subsection{4 'Transfer to Non-university Recipients'}

This criterion assessed the contribution of the institutions with respect to researchbased knowledge transfer distinguishing between 'personnel transfer' and 'knowledge transfer'. The institutions attributed different meanings to this criterium, so that the quality of the supplied entries varied accordingly. Moreover, the distinction made by the institutions between scholarly activities and those that are more likely attributable to the domain of transfer was not always comprehensible to the reviewers.

Despite the above difficulties and in view of the increasing importance of the transfer of research results, the record and assessment of transfer activities, especially to the non-university recipients, should figure prominently in the future. The distinction of the assessment aspects 'personnel transfer' and 'transfer of knowledge' was not useful since it was not always reflected in the completion of the questionnaire. In future surveys, this criterion should be defined by more distinctive aspects of assessment and more precise survey instructions.

\subsubsection{Background Information}

Within the scope of the assessment, the background information was used to qualify all other data. The background information provided about institutions and subfields 
turned out to be extremely meaningful and helpful. The possibility to describe the local conditions for the evolution of research projects allowed the reviewers to contextualize the specific research activities, in particular the publications. The information on the teaching and examination workload as well as the personnel situation helped to account for the lack of activities in other areas. For an adequate treatment of this information, self-descriptions should be kept and should not exceed a given space.

The information on vacancies in particular was extremely useful. In order to include this information even more systematically in the assessment process as well as to integrate it into the publication of the results, the collection of data needs to be standardized.

Despite the extremely high value of the background information for the qualification of the other data, it proved nevertheless insufficient. In the interest of a more objective consideration of available resources, a separate calculation and assessment of the efficiency should be included in future reviews.

\subsection{Conclusion and Outlook}

The successfully conducted pilot study of the research rating in English and American Studies shows that an adequate comparative assessment of research performance in the humanities in general, and in English and American Studies in particular, is possible. The research rating is an apt procedure to account for the particular practices of research in the humanities in the context of research assessment. This is reflected in the development and operationalization of the assessment model and in the specification of the survey period. The mode of representation according to subfields and specific criteria offers addressee-oriented information.

In October 2013, the German Council of Science and Humanities proposed recommendations for the future of the research rating (Wissenschaftsrat 2013) and suggested the extension of the research ratings to more disciplines. The experience gained from the research rating in English and American Studies was incorporated into these recommendations. The financing of the implementation is currently under discussion between federal and state governments.

\section{Chairing the Research Rating of Anglistik/Amerikanistik (by Alfred Hornung)}

The research rating Anglistik/Amerikanistik (English and American Studies) carried out under the auspices of the Wissenschaftsrat formed part of the pilot studies to assess and establish quality standards in the natural sciences and the humanities. Starting out with chemistry and sociology in 2007-2008, electrical engineering and information technology as well as English and American Studies followed in 
2011-2012. Recommended by professional associations and based on my record as member of the review board of the German Research Foundation on European and American Literatures I was asked to chair the review board. Acting on the proposals of the Steering Committee of the German Council of Science and Humanities and a subcommittee, which had developed criteria for the assessment of disciplines in the humanities, a group of eventually 19 members from England, Germany and Switzerland was selected from a list of national and international candidates, provided by their professional associations, the German Research Foundation and the Steering Committee of the Wissenschaftsrat. The Steering Committee appointed this group of reviewers and entrusted them with the research rating, supported by administrators of the Head Office (Dr. Rainer Lange, Dr. Elke Lütkemeier, Dr. Veronika Khlavna). In the first session the review board decided over the subfields of the discipline of English and American Studies and the procedure and criteria for the evaluation. Eventually four distinct subfields were defined: English linguistics, English literary and cultural studies, American Studies, and English didactics. The separate treatment of English Studies and American Studies as well as the nonrecognition of a subfield of Medieval Studies were the most controversial points in the discussions. The retrenchment of Medieval Studies, which in the past used to be a subject of English linguistics, turned out to be a fact at most universities which had sacrificed both the language and literature of the Middle Ages to new curricula in Bachelor and Masters of English degrees. The argument for the separate evaluation of the American Studies Master advanced by the Americanists was based on the interdisciplinary nature of this field of studies, which in its best representation at the John F. Kennedy Institute in Berlin, comprises the cooperation of literature, linguistics, culture, history, politics, geography and economics of North America. Indeed, the strengths of American Studies in a number of universities are based on the cooperation of these different disciplines, mostly of literature, culture, politics and history. The creation of these four subfields also necessitated an increase of the number of evaluators in American Studies and didactics of English, eventually making for a parity of respectively five colleagues in linguistics, English and American Studies, and four in didactics.

Guided by the previous pilot studies and considering the special features of disciplines in the humanities, the group eventually settled on four main criteria for the evaluation: research quality, reputation, facilitating research, transfer of research to non-university recipients. The report of the Wissenschaftsrat specifies the differentiation of aspects and problems in the evaluation of each of these categories. While the assessment of the research quality and facilitating research proved to be reliable categories, reputation and transfer were difficult to assess. This difficulty might also reflect a difference between national standards. North American and British universities are much more interested in communicating their work to their students and the public. Part of this community service is an adequate and comprehensible representation of a discipline and the profile of a department and its personnel. Such promotional activities also serve to attract students in a strongly competitive system of tertiary education. German academics, especially in the humanities, still seem to be hesitant about the promotion of their work and could learn from their English-language 
colleagues. An explanation for this hesitancy could also be the often minimal attention and the low status accorded to disciplines in the humanities in the universities as well as in the public perception. The criterion of facilitating research might contribute to a change in this respect. Facilitating research comprises all measures taken to promote the careers of young researchers in the field. Next to the often long and time-consuming processes of directing individual dissertations, the establishment of structured $\mathrm{PhD}$ programs for cohorts proved to be very advantageous. This is also reflected in the successful applications for third-party funds, especially in the constitution of research training groups funded by the German Research Foundation or other sponsors. Our review of these very positive achievements also showed that the major research universities profit most from these joint research programs. At the same time the promotion of many PhDs also necessitates the creation of new avenues for jobs outside of academic careers. In this respect, more attention needs to be directed toward transfer activities and to a more pragmatic orientation of doctoral training programs.

This diversification of research and research training also pertains to the selfconception of the four subfields of the discipline Anglistik/Amerikanistik. German linguists of the English language have successfully adapted to international standards, which also includes a trend toward publications of articles in journals instead of lengthy monographs. While the monograph still represents the major piece of original scholarship in the humanities and allows scholars also in smaller departments to document their special expertise, the publication of articles gains increasing importance. This move from monographs to articles also reflects the time available for research in most disciplines of the humanities. Next to German Studies, Anglistik/Amerikanistik has the highest number of students who pursue academic degrees or want to enter a teaching career in secondary education. Much time is spent in teaching crowded lectures and seminars and grading papers. Many colleagues of the participating universities used the sections of the questionnaire provided for background information, comments about local conditions, to point to the disparity between teaching and research and to the disregard of teaching in the evaluation process.

The coexistence of academic and teacher training curricula also makes for the hybrid nature of the discipline of Anglistik/Amerikanistik. On the one hand the subject of 'English' for future teachers unites all four subfields and combines the tasks of linguists, Anglicists, Americanists and didacticians in teaching courses with a focus on teacher training. In most instances only colleagues in the didactics of English do research in this particular area and hence often score highly in transfer to schools and the public. On the other hand each of the four subfields pursues their research interests geared primarily to academic careers and less to teacher training. Historically the common denominator used to exist in the definition of the comprehensively defined discipline of 'Anglistik' as philology. The study of etymological features of the English language and close readings of great literature basically stressed the competence of the language as a system, and courses as well as research were conducted in German. Starting in the 1980s this situation has changed with an emphasis on the practical knowledge of English and the performance of the language both in the classroom and 
in publications. This change was a response to the powerful influence of English and American popular cultures on young people as well as the increasing importance of ethnic minorities, which challenged the mainstream cultures in the English language countries of immigration: Australia, America, Canada and Great Britain, including the former Commonwealth. Consequently the common bond of philology moved into the background and the four subfields further specialized with an emphasis on cultural studies. The formation of new cooperations and exchange programs with international colleagues and institutions intensified these specializations. The call for inter- and transdisciplinary research programs in the universities corresponded with the new application programs of academic sponsors and favoured adequate research activities. Initially the interdisciplinary nature of research and training in American Studies favoured this field, a fact which also figured prominently in the number of successful applications for third-party funds.

An important part of the research rating carried out by the review board under the auspices of the Wissenschaftsrat was its acceptance by institutions, colleagues and professional associations. Early on the Wissenschaftsrat organized two meetings in Berlin and Mainz for academic and administrative coordinators from each institution to communicate the process of evaluation and assist in the collection of data about personnel, students and research activities. Representatives of the Wissenschaftsrat, Dr. Veronika Khlavna and Dr. Elke Lütkemeier, and I attended the 2011 and 2012 annual conventions of the Deutscher Anglistenverband (German Association for English Studies) and the Deutsche Gesellschaft für Amerikastudien (German Association for American Studies) as well as the meeting of the Deutsche Gesellschaft für Fremdsprachenforschung (German Association for Foreign Language Research) to inform their members about the evaluation process, to gain their support and to listen to their concerns. Apart from questions about the constitution of the review board, the subdivision of the discipline into four subfields or missing ones, such as Postcolonial Studies or Medieval Studies, the strict time-period of 7 years (2004-2010) for the assessment proved to be the most important points. Even the hybrid approach to the evaluation of current-potential and work-done-at seemed inadequate and colleagues felt that the work of emeriti and the rupture caused by vacancies were not accounted for. Also, the absence of teaching from the criteria of evaluation was criticized. The differences in department structures in terms of personnel and budget, the comprehensive conception of English as one discipline as opposed to separate subfields and their number of representatives were felt to effect the comparative analysis of ratings. A serious concern was the potential usage of the evaluation results by the authorities in the universities and ministries and pursuant repercussions. In spite of these initial reservations, our reports on first results in the 2012 conventions found more acceptable audiences and many of the concerns raised initially proved to be less relevant in the review process. Maybe the knowledge about such evaluations at American universities made for the more ready acceptance of the research rating among the Americanists.

Reservations about the evaluation of a discipline in the humanities were initially also raised by some members in the Steering Committee of the Wissenschaftsrat. The presentation of the results, however, reconciled most members with the evaluation 
process, especially since it revealed a number of analogies with the previous pilot studies, not least among them the overall average rating in research quality. At the press conference in Berlin in December 2012 journalists addressed results connected with their local universities and the relevance of the results for the discipline and their fields. My work as chair of the review board ended with a report in the general session of the Scientific Commission of the Wissenschaftsrat in January 2013. The high number of participants in the Anglistik/Amerikanistik research rating, ca. $90 \%$ of all institutions, and the reliable results convinced the members of the Commission that the research rating developed by the Wissenschaftsrat could be applied to a discipline in the humanities. The successful completion of the fourth pilot study also led to the installment of, and my participation in a committee charged to prepare the basis for the extension of the research rating to all disciplines in German universities. In October 2013 the Wissenschaftsrat discussed the recommendations of this committee and suggested the extension of the evaluation to other disciplines on a regular basis.

The work in the review board over a 2 year period was carried out in a very cooperative and communal spirit and proved to be rewarding. The feedback between the representatives of the four subfields in separate sessions as well as their cooperation in plenary sessions contributed to the speedy conclusion of the research rating and the successful rendition of the report and its communication to our colleagues at the participating institutions. It was a professional pleasure to chair these sessions and share the insights gained from the informed-peer-review of submitted data with reviewers and the participators from the Wissenschaftsrat. The basically good national and international status of the discipline Anglistik/Amerikanistik, which emerged from the evaluations and which is documented in the report, is a very satisfying compensation for our work. Feedback from the institutions and subfields as well as positive reactions from ministerial and university authorities to the research rating further substantiate its successful application in the humanities.

\section{Quo Vadis Anglistik? On Rating a Disintegrating Academic Field (by Barbara Korte)}

The German Council of Science and Humanities' 2012 review for Anglistik und Amerikanistik gave rise to controversial debate in one branch of the field in particular, namely Anglistik. This was once the denomination for English Studies, understood as the study of the English language as well as the literatures and cultures expressed in it from the middle ages to the present, as practiced within departments of English. The results of the rating process document how one traditional area in which German scholars used to occupy a leading position has been practically eliminated from English Studies at German universities: Medieval Studies has survived at only a handful of universities, and it seems to be more strongly connected with other disciplines concerned with the period than with English Studies. Conversely, the field of English Studies now comprises many new interests and specializations, and it has 
therefore split up in ways that contributed to dissent over the rating process and its categories.

The decision to run the review under the designation Anglistik and Amerikanistik was discussed in the raters' preliminary sessions and was determined to be the least controversial appellation for the field as a whole. It pays tribute to the fact that American Studies has emerged as a strong and highly visible branch within the study of English literatures and cultures, with a distinct profile defined by its region of scholarly interest (the United States, or North America if Canada is included), with specific inter- and transdisciplinary connections, an internationally renowned beacon (the Kennedy Institute in Berlin) and, last but not least, a very active association that promotes the distinct nature of American Studies (although most professorships for American Studies are still situated within departments of English). From the perspective of Amerikanistik, a separate rating category was understandably favoured over the alternative, namely to be rated in a joint group with researchers engaged in the study of all other literatures and cultures in the English language, which the assessment lumped together as Anglistik: Literatur- und Kulturwissenschaft (English literary and cultural studies). It is scholars from the latter group, or Anglisten in the narrow sense, who most frequently voiced objections to the separate rating category for Amerikanistik. The two other groups in the pilot study, namely English linguistics and English didactics, remained uncontroversial since their profiles are sufficiently distinct from literary and cultural studies in terms of research interests, methodologies and links with other disciplines.

Arguments for the joint rating of Anglistik and Amerikanistik asserted, firstly, that they still share major interests in and approaches to the study of literature, film and other areas of cultural production, and, secondly, that the separate treatment of American Studies might further promote a profiling of Amerikanistik against - and possibly even at the cost of-Anglistik: Literatur- und Kulturwissenschaft. This umbrella term also invited critique since it covers a great diversity of interests and subfields that have emerged over the years in non-Americanist English Studies: Anglistik (in the narrow sense) has re-invented itself significantly (not without impulses from American Studies), retaining its historical depth (if diminished as regards the Middle Ages) and some of its traditional philological orientations, but significantly expanding and complementing them under the influence of the various 'turns' of the past two or three decades.

The most prominent and consequential changes within Anglistik have been effected through the advance (and institutionalization) of Cultural Studies and Postcolonial Studies, for which we have now also established professorships and, in a few instances, institutes. What the Wissenschaftsrat's review understood as 'English' literary and cultural studies was therefore a much bigger and far more heterogeneous bag of scholarship than that of American Studies. It is unsurprising that there were demands to split this bundle up. It was suggested, in particular, that Postcolonial Studies has become so established in the German academic system that it should have been rated on its own, as in the case of American Studies. But how, then, could one name the rest? Could 'British' Studies contain 'Irish' Studies? And where should one stop? Should specializations in Gender Studies also be rated separately? Or 
Shakespeare Studies? The research landscape that the rating exercise was expected to chart would have then become too splintered for the results to be significant. In any case, it is undeniable that, if British, Postcolonial Studies and American Studies had been treated as one unit, the results for some universities might have been different.

However, the Wissenschaftsrat's pilot study did not only point to rifts within literary and cultural studies: The separate rating categories for linguistics and didactics, though less contested, indicate how it is taken for granted that these two areas have drifted apart from literary and cultural studies. Their umbilical connections to English Studies have not been cut, but some of the linguistic research conducted by members of English departments now seems just as closely affiliated with other linguistics or with cognitive studies, while English didactics is strongly connected to that of other foreign languages or with general didactics and pedagogy. Once more, this emphasizes that Anglistik und Amerikanistik is a vexed denomination for an academic field that has become increasingly difficult to define because of internal diversification and crossovers with other disciplines. In this respect, the 2012 study with its four groups reflects a state of disintegration that is not of purely academic interest but implies questions of an eminently political nature that affect individual scholars, individual departments and the profile of the entire field. Departments with strong overall ratings will, arguably, have a better standing within their institutions than those with weaker overall results; they might be in greater demand for collaborative projects within their institution, and hence have better chances of acquiring the third-party funding and number of doctoral students that were important criteria in the 2012 pilot study. Within departments, strongly rated subfields might desire to see their symbolic capital matched by a greater share of the budget. Weakly rated professorships might be abandoned in a department in order to strengthen more strongly rated areas, and so on.

Apart from such political consequences, the discipline might also take the rating exercise as an occasion to reflect upon where it is heading: Are we content to see the field of English Studies become increasingly split up? Do we gain or lose by progressive specializations? To what extent can our universities and departments afford or support such specialization? And how should we advise young scholars in terms of career paths? For instance, should and can English Medieval Studies be revived within the German system? It would be unrealistic to assume that the major divisions within English Studies as it currently stands are reversible. American Studies will remain strong, and Postcolonial Studies will not permit itself to be once more reduced to an appendix of 'British' (?) Studies. Yet English Studies as a whole might profit if its internal connections became more visible once again. It is not that these connections were not already there: they exist in the form of organizational units (departments of English), in the cooperation of individual scholars, and they are still implemented in courses of study, notably those that focus on English as a school subject. It is no coincidence that, of the rating's four groups, didactics was the only one with a truly integrative approach to 'English' in all its subfields: language, literature and culture, and significantly also across the Anglistik/Amerikanistik divide. Current research interests such as Transatlantic Studies, Migration Studies, Transnational 
and Globalization Studies also help to bring the branches of English Studies closer together again and to generate new research areas.

The carving up of an academic field into units suitable for rating creates a publicly visible 'image', but it also gives scholars in the field an occasion to reflect upon whether they see themselves - or their subfields - as adequately represented by that image. The image of English Studies created by the 2012 pilot study seems to have aroused more thought about divisions than about the connecting lines and common research interests that prevent the field from falling apart. A reprisal of the exercise should be sensitive to the criticism voiced against the categories used in the 2012 review. And it should introduce criteria that acknowledge not only transdisciplinary research, but also intradisciplinary activities and their importance for the future of English Studies.

Open Access This chapter is distributed under the terms of the Creative Commons AttributionNoncommercial 2.5 License (http://creativecommons.org/licenses/by-nc/2.5/) which permits any noncommercial use, distribution, and reproduction in any medium, provided the original author(s) and source are credited.

The images or other third party material in this chapter are included in the work's Creative Commons license, unless indicated otherwise in the credit line; if such material is not included in the work's Creative Commons license and the respective action is not permitted by statutory regulation, users will need to obtain permission from the license holder to duplicate, adapt or reproduce the material.

\section{References}

Statistisches Bundesamt. (2010). Bildung und Kultur. In Personal an Hochschulen (Fachserie 11 Reihe 4.4). Wiesbaden: Statistisches Bundesamt.

Wissenschaftsrat. (2008). Pilotstudie Forschungsrating. In Empfehlungen und Dokumentation. Köln: Wissenschaftsrat. Retrieved from http://www.wissenschaftsrat.de/download/ Forschungsrating/Dokumente/FAQ/Pilotstudie_Forschungsrating_2008.pdf.

Wissenschaftsrat. (2013). Pilotstudie zur Weiterentwicklung des Forschungsratings. In Ergebnisse und Dokumentation. Köln: Wissenschaftsrat. 